\title{
Phase changing nanocomposites for low temperature thermal energy storage and release
}

\author{
A. Dorigato ${ }^{*}$, P. Canclini ${ }^{1}$, S. H. Unterberger ${ }^{2,3}$, A. Pegoretti $^{1}$ \\ ${ }^{1}$ University of Trento, Department of Industrial Engineering and INSTM Research Unit Via Sommarive 9, 38123 Trento, \\ Italy \\ ${ }^{2}$ Unit for Material Technology, University of Innsbruck, Austria \\ ${ }^{3}$ Christian Doppler Laboratory for Cement and Concrete Technology, Technikerstraße 136020 Innsbruck, Austria
}

Received 2 February 2017; accepted in revised form 20 April 2017

\begin{abstract}
The aim of this paper is to develop new elastomeric phase change materials (PCM) for the thermal energy storage/release below room temperature. In particular, poly(cyclooctene) (PCO)/paraffin blends filled with various concentrations of carbon nanotubes (CNTs), were prepared by a melt compounding process. The microstructural, thermo-mechanical and electrical properties of the resulting materials were investigated.

The microstructure of these materials was characterized by the presence of paraffin domains inside the PCO, and CNTs were located only inside the paraffin domains in forms of aggregated clusters. DSC tests evidenced the existence of two distinct crystallization peaks at -10 and at $6^{\circ} \mathrm{C}$, respectively associated to the paraffin and the PCO phases, indicating that both the polymeric constituents are thermally active below room temperature. Moreover, CNT addition did not substantially alter the melting/crystallization properties of the material. Noticeable improvements of the mechanical properties and of the electrical conductivity with respect to the neat $\mathrm{PCO}$ /paraffin blend could be obtained upon CNT addition, and also thermal conductivity/diffusivity values were considerably enhanced above the percolation threshold. Finite element modeling demonstrated the efficacy of the prepared nanocomposites for applications in the thermal range from -30 to $6^{\circ} \mathrm{C}$.
\end{abstract}

Keywords: nanocomposites, phase change materials, thermal energy storage, carbon nanotubes

\section{Introduction}

It is well known that through thermal energy storage (TES) systems it is possible to store (release) thermal energy by heating (cooling) a medium in order to utilize the stored energy when required. Possible applications involve power generation systems [1-4] and building constructions [5], where about one half of the energy demand is in the form of thermal energy, and the requirement may markedly vary in time [6-8]. TES technology have been also investigated in the textiles industry for the production of 'smart' fabrics able to maintain the right temperature of the body [9-14]. Other applications could be represented by the food storage $[15,16]$ and the development of innovative solar plants [17-19].

Latent heat TES systems has recently attracted the attention of researchers, because these systems are characterized by a high energy storage density at constant temperature corresponding to the transition temperature of the phase change material (PCM) $[18,20]$. Generally speaking, a solid/liquid or a solid/solid phase transition could occur, and depending on their chemical nature these materials can be classified as organic, inorganic or eutectic. Organic PCM have several advantages [21,22] with respect to the inorganic ones. Thanks to their elevated thermal storage density,

$\overline{{ }^{*} \text { Corresponding author, e-mail: andrea.dorigato@, unitn.it }}$ (C) BME-PT 
wide phase transition temperature range, lightness and limited costs [23, 24], paraffinic waxes are the most widely investigated [21, 25-27]. However, their relatively low thermal conductivity and the possible leakage above the melting point limit their applications in several technologies [28]. Encapsulation in more stable polymer matrices [27, 29] can be a solution to avoid their flow at elevated temperature, thus forming a shape-stabilized phase change material (SSPCM) [30]. Several SSPCMs with various polymer matrices such as high-density polyethylene (HDPE) [31, 32], polypropylene (PP), acrylic resins, epoxy resins [33-35], poly(methylmethacrylate) (PMMA), polyurethane [36] block copolymer, ethylene-propylene diene monomer rubber (EPDM) [27], styrene-butadiene-styrene (SBS) triblock copolymer [32, 37], polyvinylchloride (PVC) [38] were considered. In many cases, also the PCM stabilization through the addition of inorganic nanofillers was considered [37, 39]. However, in all these investigation the encapsulating matrix did not play any active role in the thermal energy storage. Nevertheless, depending on the application and on the temperature range, also the encapsulating phase could present interesting latent heat values, thus contributing to the thermal energy storage/release processes. For this reason, in the present study a poly (cyclooctene) (PCO) matrix was considered as thermally active encapsulating polymer.

Poly(cyclooctene) (PCO) is a polyolefinic matrix based on an hydrocarbon backbone with unsaturations, synthesized starting from cyclooctene, obtained from the 1,3-butadiene and 1,5-cyclooctadiene through a metathesis reaction. In this way, both cyclic and linear structures can be formed, and the crystallinity degree can be varied changing the polymerization conditions. From a mechanical point of view, PCO behaves like an elastomer, and its application is often limited by the low melting temperature. To extend the application range above its melting temperature PCO can be crosslinked [40]. For example, the chemical crosslinking with dicumylperoxide (DCP) allows to improve the dimensional stability of the material at elevated temperatures and to enhance its mechanical properties [41, 42]. Crosslinked PCO can be therefore applied in tyres production, in the rubber recycling and in the asphalt as toughening and sound adsorbing agent. This matrix was recently utilized by our group for the production of electro-activated shape memory nanocomposite materials. In these works, it was demonstrated that it is possible to tailor the both melting temperature and the melting enthalpy of the PCO matrix by changing the crosslinker amount [41, 42].

In order to overcome the problem of the intrinsic low thermal conductivity of paraffin waxes, it was recently demonstrated that it is possible to add conductive nanofillers at limited amounts [43, 44]. In fact, several efforts has been made in the last years to investigate the thermal conductivity behaviour of polymer nanocomposites [45-50]. Interestingly, only few papers dealing with the use of paraffin with melting temperatures below ambient conditions can be found in literature $[37,51]$. In fact, the dispersion of a liquid wax in a viscous polymer matrix poses some technical difficulties. On the other hand, such paraffins could be useful for the thermal energy storage/ release in winter sport equipment. On the basis of these considerations, the objective of the present paper is to prepare and characterize nanocomposites based on crosslinked poly(cyclooctene) (PCO) and a paraffin with a melting temperature of about $10^{\circ} \mathrm{C}$, containing various amounts of carbon nanotubes (CNTs). A systematic investigation of the microstructural behavior and of the thermo-mechanical properties of the resulting materials was carried out. In order to understand the real effectiveness of the prepared materials in the energy storing/releasing at low temperatures, a finite element analysis was carried out.

\section{Experimental}

\subsection{Materials}

Chips of a Vestenamer $8012^{\circledR}$ poly(cyclooctene) (mean molecular weight $M_{\mathrm{w}}=90000$, melting temperature $=65^{\circ} \mathrm{C}$, cis/trans ratio $20 / 80$, density $0.91 \mathrm{~g} / \mathrm{cm}^{3}$ ) were provided by Evonik Degussa (Germany). DCP powder, supplied by Sigma-Aldrich (molecular weight $=270.37$, purity $98 \%$ ) was utilized as chemical crosslinker. RT10HC paraffin, with a melting point of $10^{\circ} \mathrm{C}$, was provided by Rubitherm Technologies (Germany) and stored at the liquid state in a metal tank at ambient temperature (density at $20^{\circ} \mathrm{C} 0.77 \mathrm{~kg} / \mathrm{L}$, flash point $150^{\circ} \mathrm{C}$ ). $\mathrm{NC} 7000$ multi walled carbon nanotubes (MWCNTs) with a mean diameter of $9.5 \mathrm{~nm}$, a mean length of $1.5 \mu \mathrm{m}$, and a BET surface area of $250-300 \mathrm{~m}^{2} / \mathrm{g}$ were purchased by Nanocyl SA (Belgium). 


\subsection{Preparation of the samples}

All materials (paraffin, PCO and MWCNTs) were melt compounded in a Thermo Haake Rheomix 600 internal mixer with counter-rotating rotors. After various preliminary attempts, all the blends were prepared with a $\mathrm{PCO} /$ paraffin relative weight ratio of $60 / 40$. This paraffin content represents the maximum to avoid wax leakages during the compounding process. Moreover, at this ratio the resulting samples are not greasy, regardless the CNT amount. The DCP content was fixed at $1.5 \mathrm{wt} \%$. In fact, DSC tests on neat PCO matrix (not reported for the sake of brevity) revealed how at this crosslinker concentration it is possible to prepare a $\mathrm{PCO}$ matrix with a crystallization temperature of about $-10^{\circ} \mathrm{C}$, without heavily impairing the melting enthalpy values. As reported in our previous works on PCO based nanocomposites $[41,42]$, as the DCP amount increases both the melting temperature and the melting enthalpy decreases. The temperature of the mixer was kept at $70^{\circ} \mathrm{C}$, i.e. about $16^{\circ} \mathrm{C}$ above the melting point of neat $\mathrm{PCO}$, and the rotor speed was $60 \mathrm{rpm}$. First, PCO and DCP were inserted into the chamber and mixed for 2 minutes, then the liquid paraffin was gradually added. In the nanocomposite samples CNTs were fed in the mixer after the paraffin. The total duration of the compounding process was 10 minutes. The compounded materials were then hot pressed at $180^{\circ} \mathrm{C}$ at a pressure of 10 ton for 30 minutes in a Carver hydraulic press, in order to perform the complete crosslinking of the $\mathrm{PCO}$ matrix. In this way, square sheets of $\mathrm{PCO} /$ paraffin blends and of the relative nanocomposites at different CNT amounts (1, 2, 5 and $10 \mathrm{wt} \%)$, having a thickness of about $3 \mathrm{~mm}$, were prepared. Table 1 summarizes the list of the prepared samples with the concentration of each component.

\subsection{Experimental techniques}

\subsubsection{Microstructural properties}

Optical microscopy was performed at the Institute of the Macromolecular Chemistry of the Academy of Sciences of the Czech Republic in Prague. The

Table 1. List of the prepared samples

\begin{tabular}{|l|c|c|c|c|}
\hline \multicolumn{1}{|c|}{ Samples } & $\begin{array}{c}\text { PCO } \\
{[\mathbf{w t} \%]}\end{array}$ & $\begin{array}{c}\text { RT10HC } \\
{[\mathbf{w t} \%]}\end{array}$ & $\begin{array}{c}\text { DCP } \\
{[\mathbf{w t} \%]}\end{array}$ & $\begin{array}{c}\text { CNT } \\
{[\mathbf{w t} \%]}\end{array}$ \\
\hline $10 \mathrm{HC} / \mathrm{PCO}$ & 59.1 & 39.3 & 1.5 & 0 \\
\hline $10 \mathrm{HC} / \mathrm{PCO} / \mathrm{CNT} 1 \%$ & 58.5 & 39,0 & 1.5 & 1 \\
\hline $10 \mathrm{HC} / \mathrm{PCO} / \mathrm{CNT} 2 \%$ & 57.9 & 38.6 & 1.5 & 2 \\
\hline $10 \mathrm{HC} / \mathrm{PCO} / \mathrm{CNT} 5 \%$ & 56.1 & 37.4 & 1.5 & 5 \\
\hline $10 \mathrm{HC} / \mathrm{PCO} / \mathrm{CNT} 10 \%$ & 53.2 & 35.5 & 1.5 & 10 \\
\hline
\end{tabular}

samples were cut with a Leica RM2235 microtome and observed with a Leica DM6000M microscope. Field emission scanning electron microscopy (FESEM) observations of the cryofractured surfaces of the specimens were performed through a Zeiss Supra 40 microscope, operating at an acceleration voltage of $3.0 \mathrm{kV}$.

\subsubsection{Thermal properties}

Differential scanning calorimetry (DSC) was carried out with a Mettler DSC30 machine under a nitrogen flow of $150 \mathrm{~mL} / \mathrm{min}$. Heating/cooling rate was set at $10^{\circ} \mathrm{C} / \mathrm{min}$ for all the measurements, starting from -80 up to $100^{\circ} \mathrm{C}$. In this way, melting/crystallization temperatures $\left(T_{\mathrm{m}}, T_{\mathrm{c}}\right)$ and melting/crystallization enthalpy $\left(\Delta H_{\mathrm{m}}, \Delta H_{\mathrm{c}}\right)$ of paraffin and of the PCO matrix were determined.

\subsubsection{Mechanical properties}

Uniaxial tensile tests were performed with an Instron 4502 tensile testing machine equipped with a $1 \mathrm{kN}$ load cell on ISO 527 1BA type specimens. Tests were performed at a testing speed of $1 \mathrm{~mm} / \mathrm{min}$ for the determination of the elastic modulus $(E)$ and at $50 \mathrm{~mm} / \mathrm{min}$ for the determination of the stress at yield $\left(\sigma_{\mathrm{y}}\right)$. Eight specimens were tested for each sample. Shore A hardness test were performed at room temperature with a Hildebrand Durometer OS-2. According to the DIN 53505 standard, Shore A values were recorded after that the load was applied for 3 seconds.

\subsubsection{Electrical properties}

Electrical resistivity measurements were performed under a four point configuration according to the ASTM D4496-04 standard. An IPS 303DD voltage generator was connected to the sample, and the current flowing through the sample was measured with an amperometer. A voltmeter was connected to the sample at a distance of $3.69 \mathrm{~mm}$, in order to measure the voltage drop between the inner electrodes. The resistivity value was determined at different voltage levels $(2,5,10,12,24,30 \mathrm{~V})$, through the expression reported in Equation (1):

$\rho=R \cdot \frac{A}{t}$

where $R$ is the electrical resistance [ $\Omega], A$ is the cross area of the specimen $\left[\mathrm{cm}^{2}\right]$ and $t$ is the distance between the two inner probes where the voltage is 
measured $[\mathrm{cm}]$. In order to evaluate the surface heating upon voltage application by Joule effect, a Flir E6 thermal IR thermographic camera was used. Nanocomposites samples were tested at $12 \mathrm{~V}$ for $120 \mathrm{~s}$. The evolution of the surface temperature as a function of the time was monitored and recorded.

\subsubsection{Thermal conductivity/diffusivity}

Thermal conductivity/diffusivity properties were determined through laser flash measurements by using a Netzsch LFA 447 machine. One side of a disc sample was exposed to an energy pulse from a light source (laser or xenon flash lamp), measuring the temperature history on the other side using a liquid nitrogen cooled infrared detector. The thermal properties of the samples were measured at three different temperatures $\left(20,40\right.$ and $\left.60^{\circ} \mathrm{C}\right)$, performing 3 shots respectively. Data were analysed using the software Proteus. Thermal diffusivity $(\alpha)$ was calculated using the Cowan approach with pulse correction. For the determination of the heat capacity $\left(c_{\mathrm{p}}\right)$, a standard Pyrex 7740 reference material prepared according to ASTM-E 1461 standard was measured and compared with the samples. Sample density $(\rho)$ was calculated based on measured sample dimensions and mass, and the thermal conductivity $(\lambda)$ was determined through the Equation (2):

$$
\lambda=\alpha \rho c_{p}
$$

In order to interpret thermal conductivity data at $20^{\circ} \mathrm{C}$, three different models that are commonly used in literature for polymer composites were considered. The expression of the parallel model is reported in Equation (3), while the expressions of the geometric mean model and of the Maxwell-Eucken model are reported in Equation (4) and in Equation (5), respectively:

$\frac{1}{\lambda_{\mathrm{c}}}=\frac{1-\varphi}{\lambda_{\mathrm{m}}}+\frac{\varphi}{\lambda_{\mathrm{f}}}$

$\lambda_{\mathrm{c}}=\lambda_{\mathrm{m}}^{1-\varphi} \lambda_{\mathrm{f}}^{\varphi}$

$\lambda_{\mathrm{c}}=\lambda_{\mathrm{m}} \frac{2 \lambda_{\mathrm{m}}+\lambda_{\mathrm{f}}+2 \varphi\left(\lambda_{\mathrm{f}}-\lambda_{\mathrm{m}}\right)}{2 \lambda_{\mathrm{m}}+\lambda_{\mathrm{f}}-\varphi\left(\lambda_{\mathrm{f}}-\lambda_{\mathrm{m}}\right)}$

where $\lambda_{\mathrm{m}}, \lambda_{\mathrm{f}}$ and $\lambda_{\mathrm{c}}$ represent the thermal conductivity of the matrix, of the filler (taken as $2000 \mathrm{~W} /(\mathrm{m} \cdot \mathrm{K}$ ) according to [52]) and of the composite, respective$\mathrm{ly}$, and $\varphi$ is the filler volume fraction.

\subsubsection{FEM analysis}

In order to evaluate the effectiveness of the prepared materials as possible candidates for the winter sports equipment, a finite element method (FEM) analysis was performed by using Ansys 14.0 software (Ansys Italia Srl, Italy). At this aim two materials, based on the $10 \mathrm{HC} / \mathrm{PCO} / \mathrm{CNT} 2 \%$ nanocomposite sample, were compared. These materials are assumed to have the same density $\left(1220 \mathrm{~kg} / \mathrm{m}^{3}\right)$, specific heat $(1988 \mathrm{~J} /(\mathrm{kg} \cdot \mathrm{K}))$ and thermal conductivity $(0.299 \mathrm{~W} /(\mathrm{m} \cdot \mathrm{K}))$, but the first one (called 'with latent heat') has the capability to release during solidification a latent heat of $104.8 \mathrm{~J} / \mathrm{g}$ (according to calorimetric tests), while the other one (called 'without latent heat') does not release any latent heat during cooling. However, for both materials a thermal contribution due to sensible heat is considered during the cooling process.

Two different models were analyzed: the phase change material (PCM) model and the 'glove' model. In the first case (PCM model), the phase change material had an initial temperature of $20^{\circ} \mathrm{C}$ and it was suddenly exposed to an external temperature of $-30^{\circ} \mathrm{C}$. A $2 \mathrm{D}$ rectangular sample $1 \mathrm{~cm} \times 3 \mathrm{~cm}$ was considered, and the evolution of the temperature on the edges of the material at different times was determined. In this model, a convection heat transfer coefficient of $30 \mathrm{~W} /\left(\mathrm{m}^{2} \cdot \mathrm{K}\right)$ was assumed. In the second case ('glove' model), the phase change material was used to cover another materials representing a human finger (a 2D rectangular sample $1 \mathrm{~cm} \times 3 \mathrm{~cm}$ ), that was created considering the thermal properties $3349 \mathrm{~J} /(\mathrm{kg} \cdot \mathrm{K})$, thermal conductivity $=0.370 \mathrm{~W} /(\mathrm{m} \cdot \mathrm{K})$ ). The system had an initial temperature of $20^{\circ} \mathrm{C}$, and it was suddenly exposed to an external temperature of $-30^{\circ} \mathrm{C}$. Also for this model, a convection heat transfer coefficient of $30 \mathrm{~W} /\left(\mathrm{m}^{2} \cdot \mathrm{K}\right)$ was considered. The thickness of the coating material was varied from 0.5 up to $5.0 \mathrm{~mm}$, and the temperature evolution at the interface between the finger and the coating was estimated at various time intervals.

\section{Results and discussion}

\subsection{Microstructural properties}

In Figure 1 optical microscopy images of the PCO/ paraffin blends and of the relative nanocomposites are reported. In all samples it is possible to observe the presence of rectangular domains of paraffin inside the encapsulating phase (i.e. PCO), having the major 


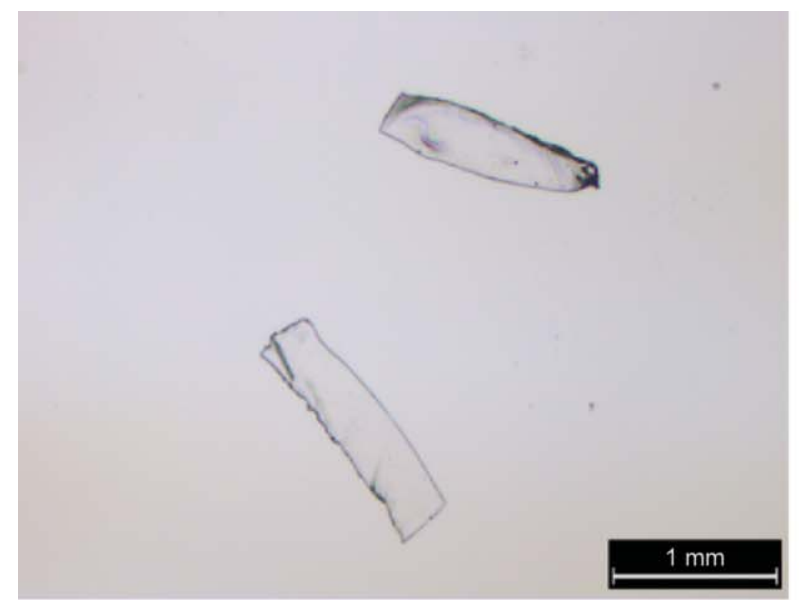

10HC/PCO
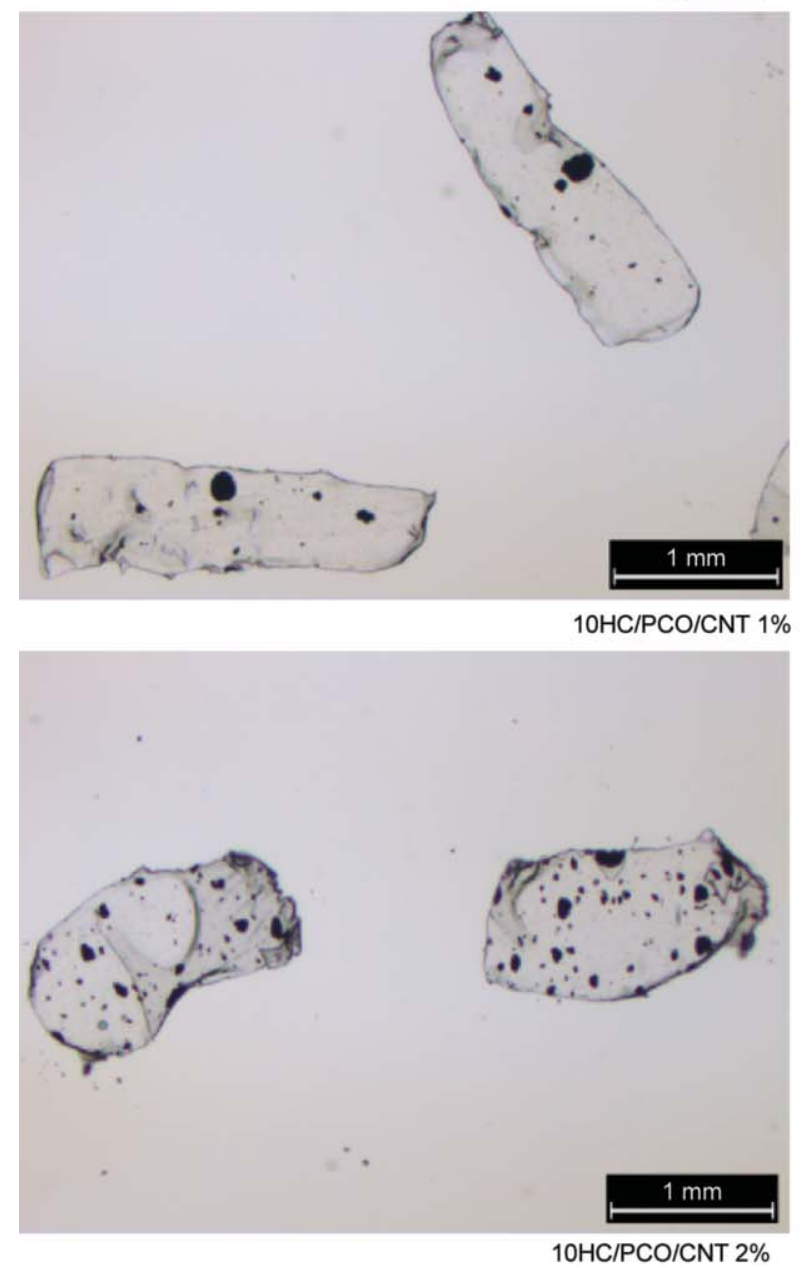

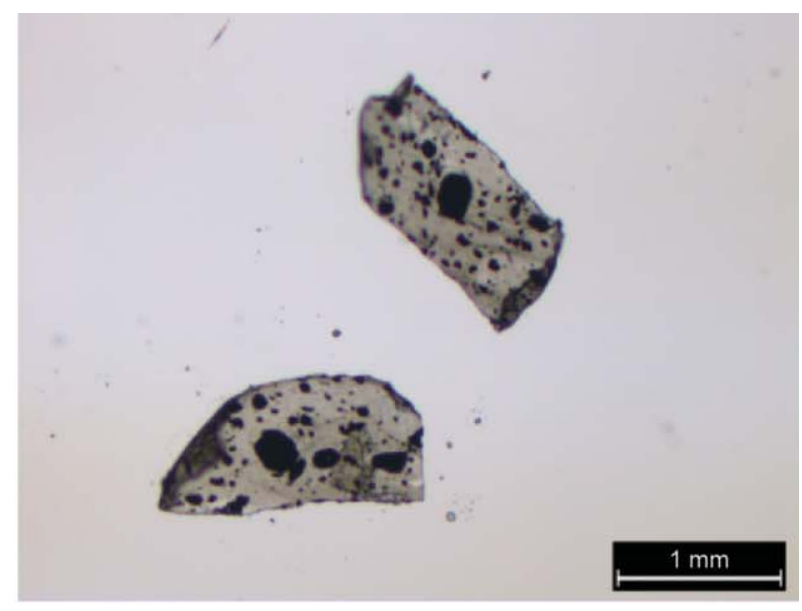

10HC/PCO/CNT 5\%

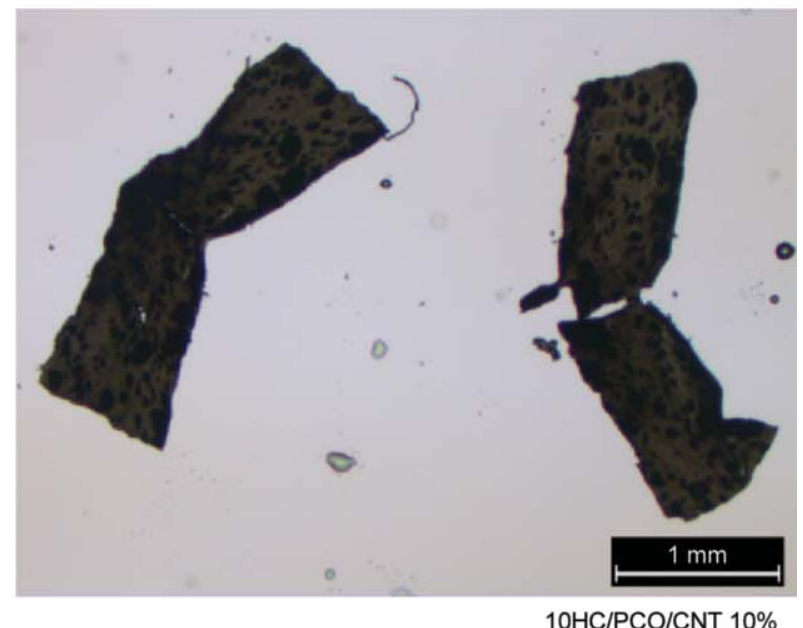

10HC/PCO/CNT 10\%

Figure 1. Optical microscopy images of $\mathrm{PCO} /$ paraffin blend and of the relative nanocomposites

dimension in the order of $1 \mathrm{~mm}$. It is interesting to note how in the nanofilled sample CNTs are distributed only inside the paraffin, forming clusters of $0.1-$ $0.2 \mathrm{~mm}$ in the $10 \mathrm{HC} / \mathrm{PCO} / \mathrm{CNT} 1 \%$ sample. Increasing the nanofiller amount, the dimensions of these clusters increase. Above the $2 \mathrm{wt} \%$ of CNTs also some little clusters appear to be homogeneously dispersed in the paraffin domains. This microstructural feature could be probably ascribed to the preparation process of the composites. The CNTs were preferentially dispersed in the liquid phase, but the low affinity between CNTs and paraffin determined an evident nanofiller aggregation.

In Figure 2 FESEM micrographs of the PCO/paraffin blend and of the relative nanocomposites samples are reported. In this case it is not possible to distinguish the paraffin and the PCO phases inside the materials, but the micrographs confirm a strong CNT 


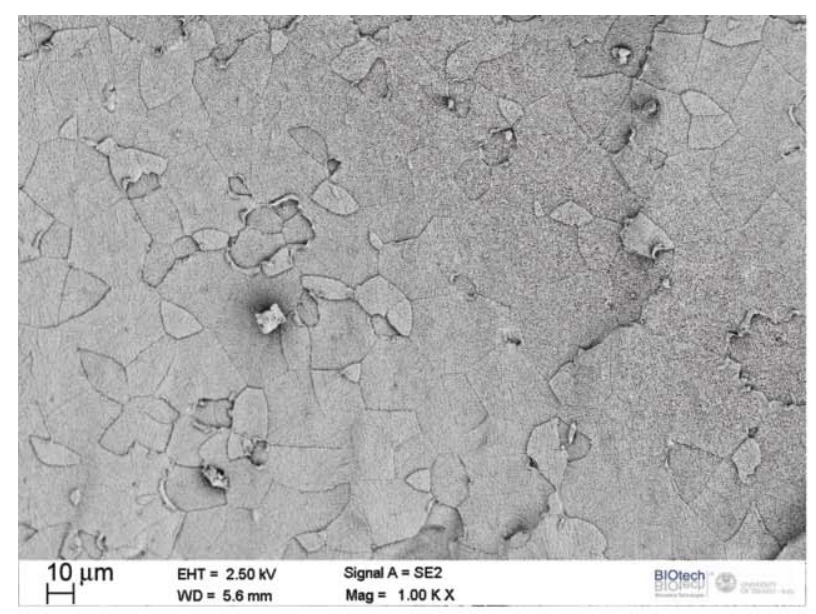

a)

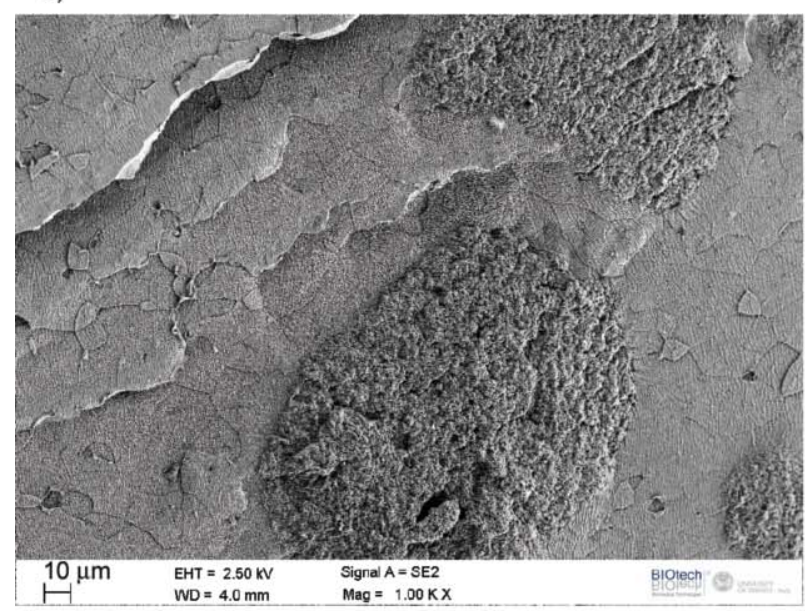

c)

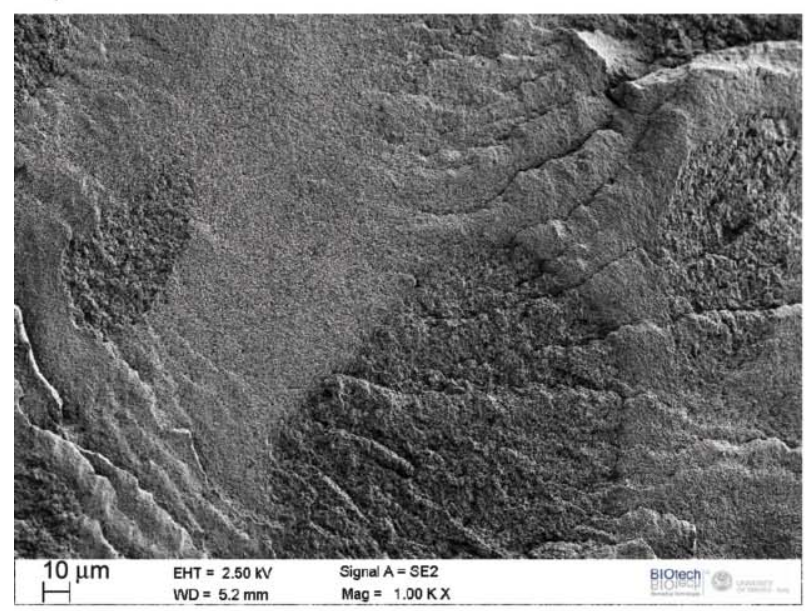

e)

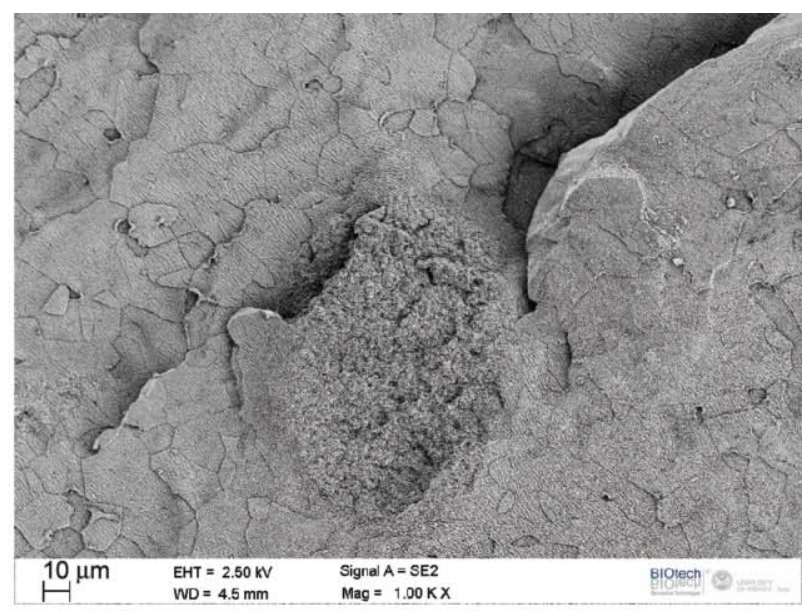

b)

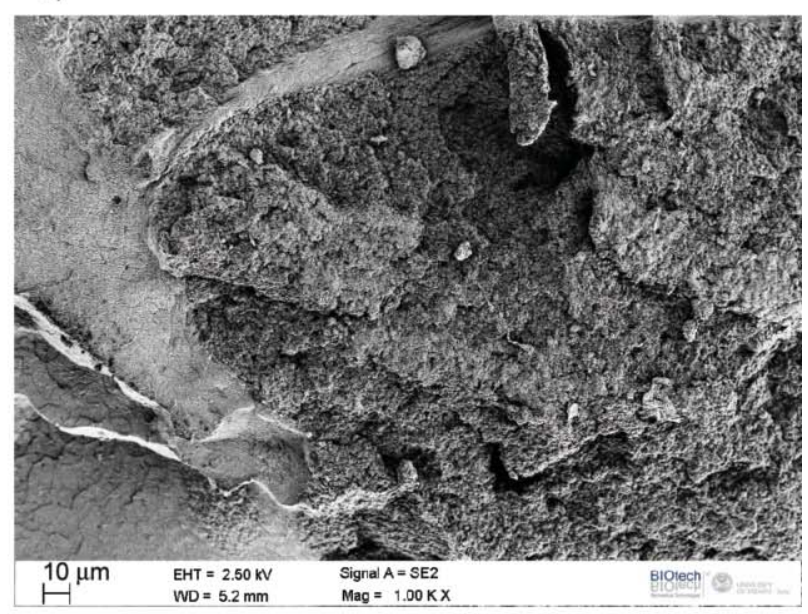

d)

Figure 2. FESEM micrographs of PCO/paraffin blend and of the relative nanocomposites. (a) 10HC/PCO, (b) $10 \mathrm{HC} /$ $\mathrm{PCO} / \mathrm{CNT} 1 \%$, (c) $10 \mathrm{HC} / \mathrm{PCO} / \mathrm{CNT} 2 \%$, (d) $10 \mathrm{HC} / \mathrm{PCO} / \mathrm{CNT} 5 \%$, (e) $10 \mathrm{HC} / \mathrm{PCO} / \mathrm{CNT} 10 \%$.

aggregation within the material, and the clusters size increases with the nanofiller amount. The observed microstructural behaviour could probably limit the thermal/ electrical conductivity properties of the prepared nanocomposites, and several efforts will be made in the future to improve the nanofiller dispersion within the matrix.

\subsection{Thermal properties}

The possibility to apply PCMs in engineering applications is related to their capability to store/release thermal energy in a useful temperature interval. Therefore, the investigation of the thermal properties of the prepared specimens plays a key role in the present investigation. In Figure 3 DSC thermograms 

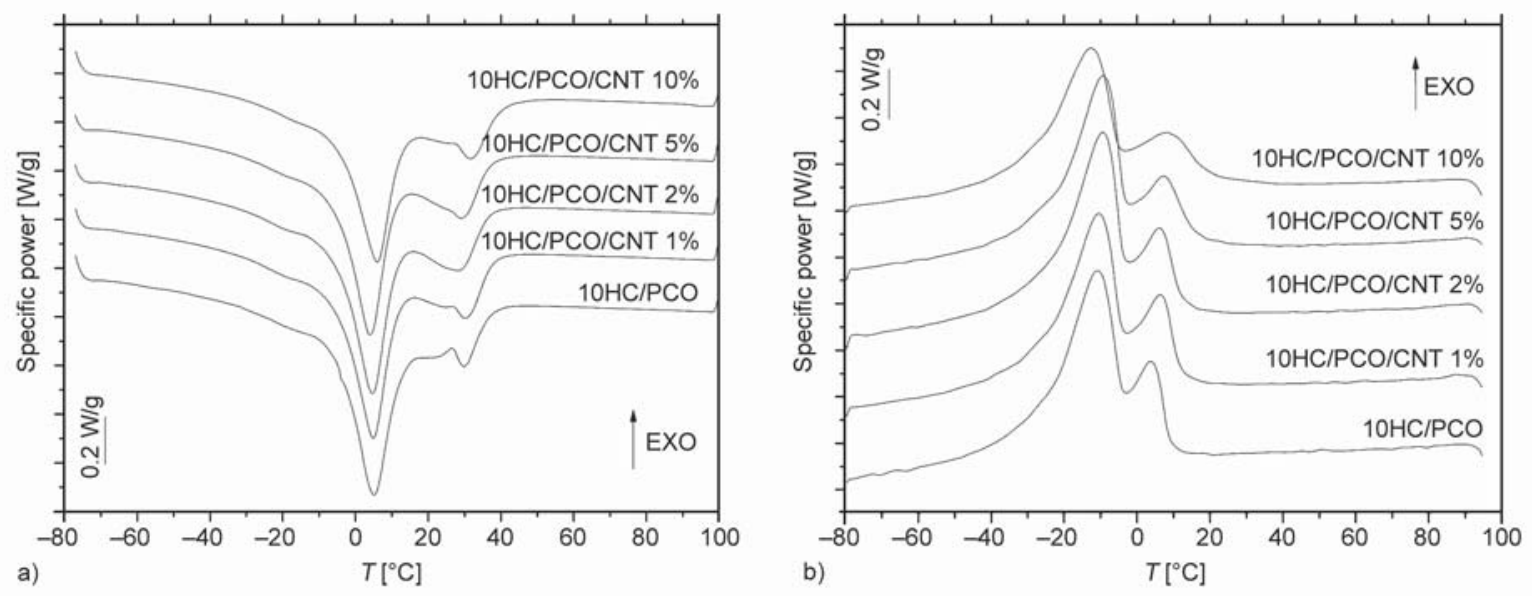

Figure 3. DSC thermograms of PCO/paraffin blend and of the relative nanocomposites. (a) First heating scan and (b) cooling scan.

of the $\mathrm{PCO} /$ paraffin blend and of the relative nanocomposites during the first heating and the cooling scans are shown. From a qualitative point of view, all the thermograms present the same trends. In Figure $3 \mathrm{a}$ the melting peak at low temperature (about $5^{\circ} \mathrm{C}$ ) is associated to the melting of the paraffin, while the second endothermic signal at about $30^{\circ} \mathrm{C}$ is related to the melting of the PCO. As it could be expected, the intensity of the peak associated to the melting of the paraffin component is higher than that of the PCO, because of the higher melting enthalpy values of the PCM. A similar trend can be detected in the cooling stage (Figure $3 b$ ): the crystallization peak of the paraffin is located at $-10^{\circ} \mathrm{C}$, while that of the PCO is at about $6^{\circ} \mathrm{C}$. The most important results from DSC tests are summarized in Table 2. DSC tests on neat paraffin and on PCO with $1.5 \%$ of DCP (not reported for the sake of brevity) provided $\Delta H_{\mathrm{m}}$ and $\Delta H_{\mathrm{m}}^{\prime}$ values of 212.6 and $61.6 \mathrm{~J} / \mathrm{g}$, respectively. In Table $2, \Delta H_{\mathrm{m}}$ and $\Delta H_{\mathrm{m}}^{\prime}$ values for the $10 \mathrm{HC} / \mathrm{PCO}$ blend and all the composites are about $80-90$ and $25 \mathrm{~J} / \mathrm{g}$, respectively. Considering the relative amount of the polymer phases within the material, it can be therefore concluded that melting enthalpy values of the paraffin are not impaired by the physical blending with PCO, while for the poly(cyclooctene) matrix a slight reduction of the melting enthalpy values due to the physical blending can be detected. It is evident that the introduction of the CNTs does not substantially affect the position of the melting/crystallization peaks. It is also important to underline that the experienced decrease of the total melting/crystallization enthalpy values with the CNT amount is practically due only to the decrease of the polymeric fraction in the material, and the presence of the nanofiller does not substantially hinder the melting/crystallization process of the material. For all the materials, melting/crystallization enthalpy values between 98 and $116 \mathrm{~J} / \mathrm{g}$ were obtained. Considering the DSC thermograms in the cooling stage, it is also interesting to note that the position of both the melting peaks (i.e. 6 and $-10{ }^{\circ} \mathrm{C}$ ) are useful to exploit the prepared materials in winter sport application, and also the encapsulating phase (i.e. the

Table 2. Results of DSC tests on PCO/paraffin blend and of the relative nanocomposites (first heating and cooling cycles)

\begin{tabular}{|c|c|c|c|c|c|}
\hline \multicolumn{6}{|c|}{ Heating } \\
\hline Samples & $\begin{array}{c}\boldsymbol{T}_{\mathrm{m}} \\
{\left[{ }^{\circ} \mathbf{C}\right]}\end{array}$ & $\begin{array}{c}T_{\mathrm{m}^{\prime}} \\
{\left[{ }^{\circ} \mathbf{C}\right]}\end{array}$ & $\begin{array}{l}\Delta H_{\mathrm{m}} \\
{[\mathrm{J} / \mathrm{g}]}\end{array}$ & $\begin{array}{c}\Delta H^{\prime}{ }_{m} \\
{[\mathbf{J} / \mathbf{g}]}\end{array}$ & $\underset{[\mathbf{J} / \mathbf{g}]}{\Delta \boldsymbol{H}_{\mathrm{mTOT}}}$ \\
\hline $10 \mathrm{HC} / \mathrm{PCO}$ & 5.1 & 29.8 & 90.5 & 15.7 & 106.2 \\
\hline $10 \mathrm{HC} / \mathrm{PCO} / \mathrm{CNT} 1 \%$ & 4.8 & 30.1 & 81.9 & 24.8 & 106.6 \\
\hline $10 \mathrm{HC} / \mathrm{PCO} / \mathrm{CNT} 2 \%$ & 4.7 & 28.4 & 81.3 & 27.2 & 108.6 \\
\hline $10 \mathrm{HC} / \mathrm{PCO} / \mathrm{CNT} 5 \%$ & 4.0 & 29.2 & 73.8 & 23.9 & 97.8 \\
\hline $10 \mathrm{HC} / \mathrm{PCO} / \mathrm{CNT} 10 \%$ & 6.0 & 31.5 & 73.3 & 24.5 & 97.8 \\
\hline \multicolumn{6}{|c|}{ Cooling } \\
\hline Samples & $\begin{array}{c}T_{\mathbf{c}} \\
{\left[{ }^{\circ} \mathbf{C}\right]}\end{array}$ & $\begin{array}{c}T_{\mathrm{c}}{ }^{\prime} \\
{\left[{ }^{\circ} \mathbf{C}\right]}\end{array}$ & $\begin{array}{l}\Delta H_{\mathrm{c}} \\
{[\mathrm{J} / \mathrm{g}]}\end{array}$ & $\begin{array}{l}\Delta \boldsymbol{H}_{\mathbf{c}}^{\prime} \\
{[\mathbf{J} / \mathbf{g}]}\end{array}$ & $\begin{array}{c}\Delta H_{\text {стот }} \\
{[\mathbf{J} / \mathbf{g}]}\end{array}$ \\
\hline $10 \mathrm{HC} / \mathrm{PCO}$ & -11.0 & 3.7 & 93.6 & 22.8 & 116.4 \\
\hline $10 \mathrm{HC} / \mathrm{PCO} / \mathrm{CNT} 1 \%$ & -10.5 & 6.3 & 76.1 & 25.9 & 102.0 \\
\hline $10 \mathrm{HC} / \mathrm{PCO} / \mathrm{CNT} 2 \%$ & -9.4 & 6.1 & 80.8 & 24.0 & 104.8 \\
\hline $10 \mathrm{HC} / \mathrm{PCO} / \mathrm{CNT} 5 \%$ & -9.3 & 7.1 & 77.1 & 25.6 & 102.7 \\
\hline $10 \mathrm{HC} / \mathrm{PCO} / \mathrm{CNT} 10 \%$ & -12.5 & 7.9 & 76.9 & 26.6 & 103.5 \\
\hline
\end{tabular}

$T_{\mathrm{m}}-\quad$ melting temperature of the paraffin

$T_{\mathrm{m}}{ }^{\prime}-\quad$ melting temperature of PCO

$\Delta H_{\mathrm{m}}-\quad$ melting enthalpy of the paraffin

$\Delta H_{\mathrm{m}}^{\prime}-$ melting enthalpy of PCO

$\Delta H_{\text {mTOT }}-$ total melting enthalpy

$T_{\mathrm{c}}-\quad$ crystallization temperature of the paraffin

$T_{\mathrm{c}}{ }^{\prime}-\quad$ crystallization temperature of the PCO

$\Delta H_{\mathrm{c}}-\quad$ crystallization enthalpy of the paraffin

$\Delta H_{\mathrm{c}}^{\prime}-\quad$ crystallization enthalpy of the PCO

$\Delta H_{\mathrm{cTOT}}-$ total crystallization enthalpy 
PCO) can give a positive contribution to the heat release process at low temperature. It can be therefore concluded that a proper selection of the encapsulating matrix (i.e. PCO with $1.5 \% \mathrm{DCP}$ ) can allow the preparation of physical blends in which both the materials contribute to the heat release/absorption in a certain temperature range. However, it is important to underline that DSC tests with multiple heating/ cooling cycles should be performed in order to assess the reliability of the tested PCM materials. This activity will be probably inserted in a future paper on the thermal properties of these systems.

\subsection{Mechanical properties}

In Figure 4a representative stress-strain curves of the $\mathrm{PCO} /$ paraffin blend and of the relative nanocomposites are reported, while in Figure $4 \mathrm{~b}$ the trends of the elastic modulus $(E)$ and of the stress at yield $\left(\sigma_{\mathrm{y}}\right)$ as a function of the CNT amount are represented. All the tested material present the typical behaviour of an elastomer, but it is clearly evident that CNT addition is responsible of a noticeable increase of both the elastic modulus and of the yield stress. For instance, with a CNT amount of $10 \mathrm{wt} \%$ it is possible to obtain $E$ and $\sigma_{\mathrm{y}}$ increments of 575 and $250 \%$, respectively. The strong dependency of the material stiffness of the nanofilled samples from the filler aggregation was highlighted in a recent article of our group, in which a new theoretical model was proposed to model the elastic properties of particulate nanocomposites [53]. In that paper, it was evidenced how nanofiller aggregation may constrain a portion of matrix, thus limiting the mobility of macromolecules and providing a stiffening effect. A modification of the aggregative state of the nanoparticles could be therefore responsible of the variations of the elastic modulus observed
Table 3. Results of Shore A hardness tests on PCO/paraffin blend and of the relative nanocomposites

\begin{tabular}{|l|c|}
\hline \multicolumn{1}{|c|}{ Samples } & Shore A hardness \\
\hline $10 \mathrm{HC} / \mathrm{PCO}$ & $46 \pm 1$ \\
\hline $10 \mathrm{HC} / \mathrm{PCO} / \mathrm{CNT} 1 \%$ & $49 \pm 1$ \\
\hline $10 \mathrm{HC} / \mathrm{PCO} / \mathrm{CNT} 2 \%$ & $48 \pm 1$ \\
\hline $10 \mathrm{HC} / \mathrm{PCO} / \mathrm{CNT} 5 \%$ & $56 \pm 1$ \\
\hline $10 \mathrm{HC} / \mathrm{PCO} / \mathrm{CNT} 10 \%$ & $71 \pm 1$ \\
\hline
\end{tabular}

for the tested materials. As it could be expected, the strong nanofiller aggregation evidenced in optical microscope and in FESEM micrographs is responsible of a decrease of the strain at break values (from 450 to $200 \%$ with a CNT concentration of $10 \mathrm{wt} \%$ ). Similar trends were detected in our previous work on PCO based nanocomposites [41]. Shore A hardness values reported in Table 3 confirm the efficacy of CNTs in increasing the mechanical stability of the material. In fact, $10 \mathrm{HC} / \mathrm{PCO} / \mathrm{CNT} 10 \%$ sample presents a Shore A value of 71, 24 points higher than that of the unfilled blend. It can be therefore concluded that CNT addition strongly improves the mechanical performances of the material.

\subsection{Electrical properties}

In Figure 5a electrical resistivity values of 5 and $10 \mathrm{wt} \%$ nanocomposite samples are reported as a function of the applied voltage. For the nanocomposites at lower filler amounts it was not possible to measure the resistivity values, probably because their resistivity was too high for the equipment at our disposal. The tested materials present a typical ohmic behaviour, with resistivity values independent from the applied voltage. With a CNT content of 5 and $10 \mathrm{wt} \%$, resistivity values of $3 \cdot 10^{2}$ and $5 \cdot 10^{0} \Omega \cdot \mathrm{cm}$ can be respectively obtained. These results are comparable
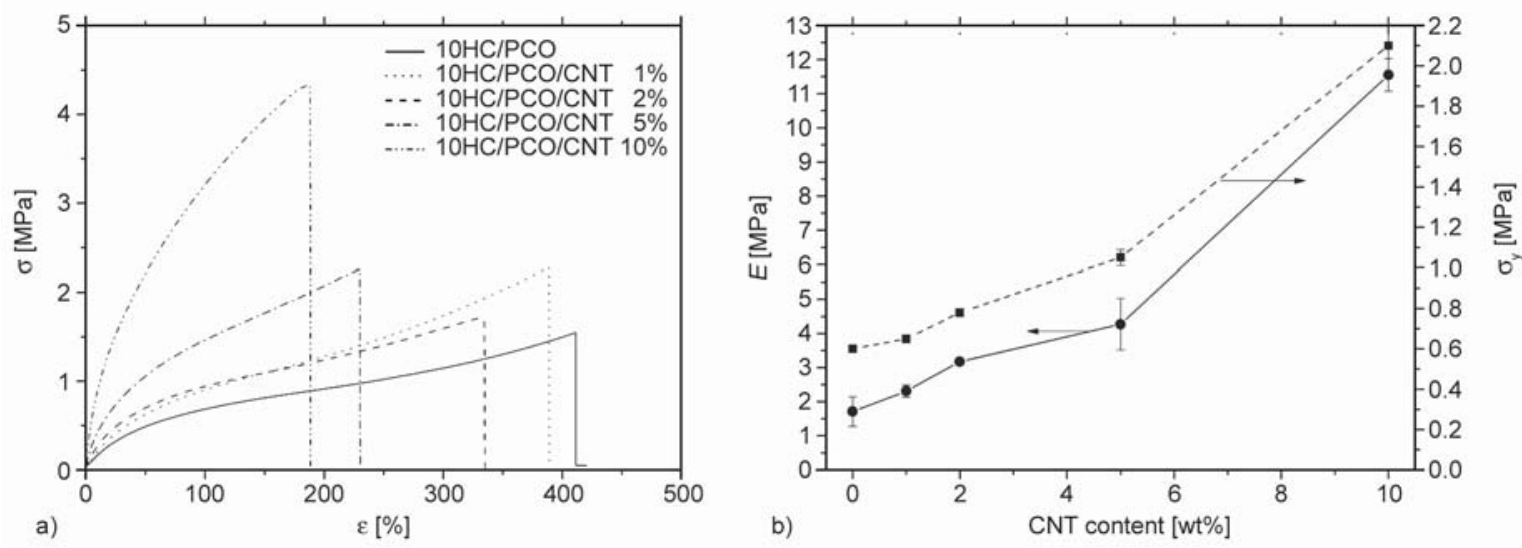

Figure 4. Mechanical properties of $\mathrm{PCO}$ /paraffin blend and of the relative nanocomposites. (a) Representative stress-strain curves, (b) elastic modulus $(E)$ and stress at yield $\left(\sigma_{\mathrm{y}}\right)$ trends as a function of the CNT content. 

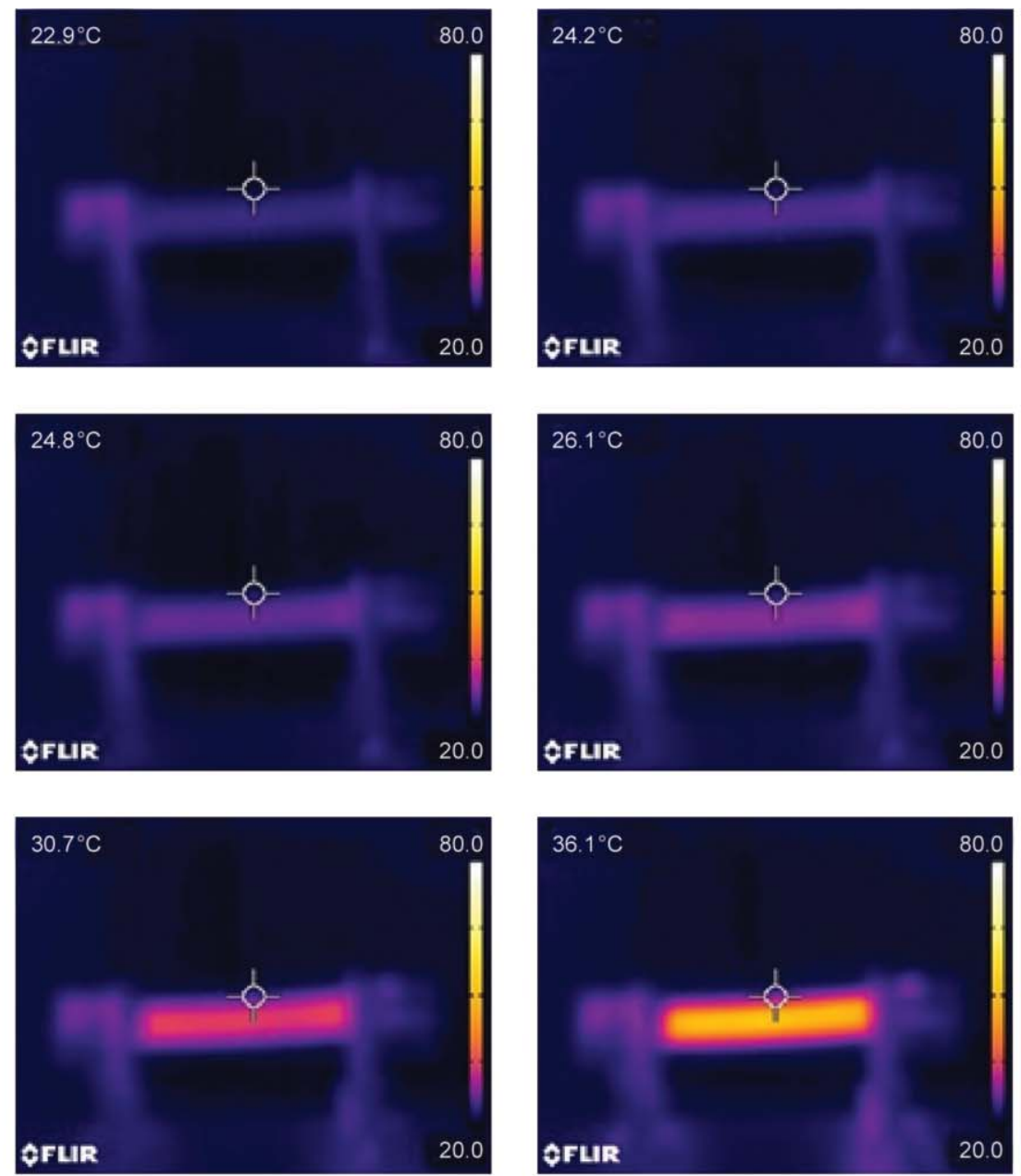

b)
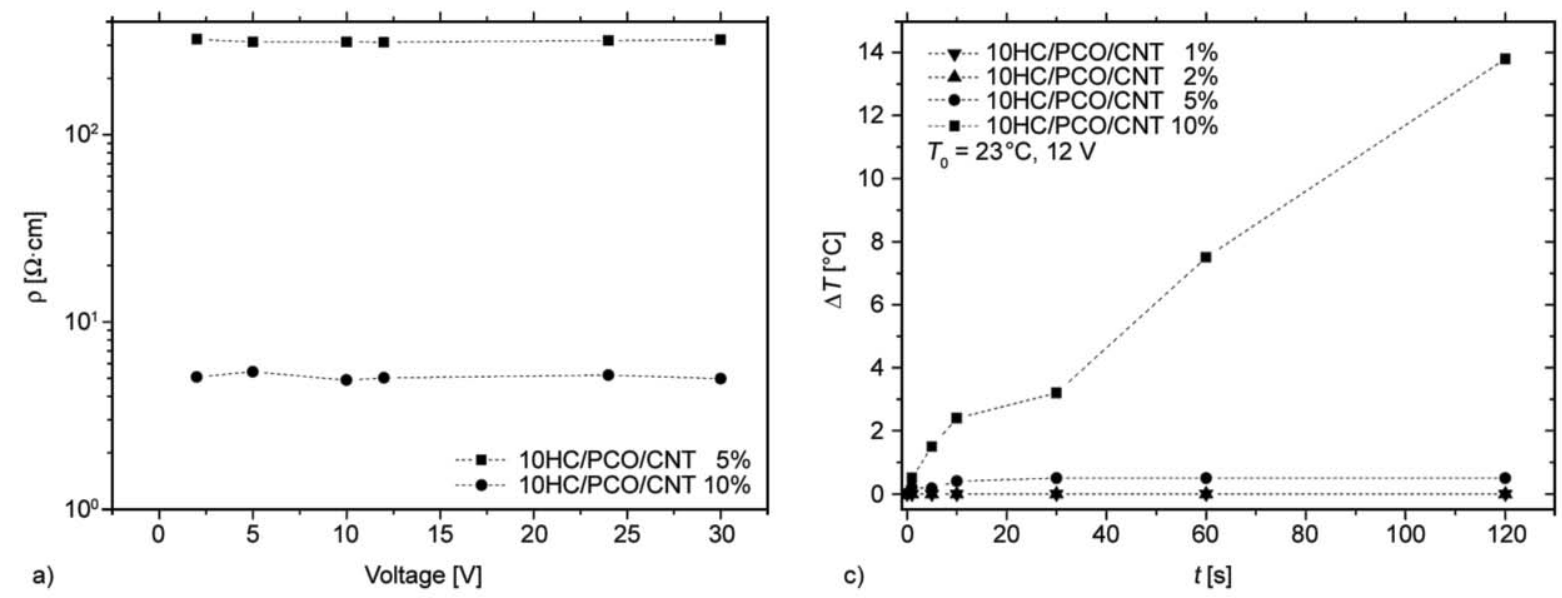

Figure 5. Electrical properties of the PCO/paraffin based nanocomposites. (a) Resistivity over the applied voltage, (b) thermographs of the surface heating of the $10 \mathrm{HC} / \mathrm{PCO} / \mathrm{CNT} 10 \%$ sample (applied voltage $12 \mathrm{~V}$ ), (c) surface temperature evolution (applied voltage $12 \mathrm{~V}$ ).

with those obtained by our group on other polymeric systems filled with carbonaceous nanofillers [50]. Improving the dispersion quality of CNTs within the materials, lower electrical resistivity values would be probably obtained even at limited filler amounts. Another feature related to the electrical conductivity of the prepared materials is their capability to be heated through the Joule effect upon voltage application. In Figure 5b representative thermograms of the $10 \mathrm{wt} \%$ nanocomposite sample heated applying a voltage of $12 \mathrm{~V}$ is reported, while in Figure $5 \mathrm{c}$ the surface temperature evolution with time of all the prepared samples at $12 \mathrm{~V}$ is represented. As it could be expected, nanocomposite samples with a CNT 
amount lower than $5 \mathrm{wt} \%$ do not show any temperature increment after $120 \mathrm{~s}$, while for the $10 \mathrm{HC} / \mathrm{PCO} /$ CNT 5\% sample a very limited temperature increase (less than $1{ }^{\circ} \mathrm{C}$ ) can be detected. Only the nanocomposites sample filler with $10 \mathrm{wt} \%$ of CNT evidences an interesting increase of the surface temperature at $12 \mathrm{~V}\left(14^{\circ} \mathrm{C}\right.$ after $\left.120 \mathrm{~s}\right)$. Once again, a better nanofiller dispersion would probably help in improving the Joule heating effect in the prepared materials.

\subsection{Thermal conductivity/diffusivity}

For phase change materials the evaluation of the thermal conductivity/diffusivity is of crucial importance, and nanofiller addition generally helps in improving the heat conduction within the material [37]. In Figure $6 \mathrm{a}-6 \mathrm{c}$ the trends of the most important thermal properties of the prepared materials (i.e. specific heat, thermal diffusivity and thermal conductivity) are respectively reported as a function of the CNT amount at three different testing temperatures. Concerning $c_{\mathrm{p}}$ values (Figure 6a), it is interesting to note that specific heat decreases with the testing temperature but its value is not substantially affected by nanofiller addition, at remains at a value of around $2.0 \mathrm{~J} /(\mathrm{kg} \cdot \mathrm{K})$ for all the tested materials. Generally speaking, specific heat capacity of a polymeric material should increase with the testing temperature. However, in the present case heat capacity is strongly influenced by phase changing process. Typically, $c_{\mathrm{p}}$ increases strongly around glass transition and crystalline melting temperatures. Within the temperature range from 20 to $40^{\circ} \mathrm{C}$, important thermal transitions can be detected for the investigated materials (see DSC tests in Figure $3 \mathrm{a}$ and $3 \mathrm{~b}$ ). These transitions could probably explain the higher $c_{\mathrm{p}}$ values at 20 and $40^{\circ} \mathrm{C}$ with respect to those detected at $60^{\circ} \mathrm{C}$. This hypothesis is supported by the conclusions reported in some literature papers [54]. Also the thermal diffusivity and the thermal conductivity decrease with the temperature, but important enhancements of $\alpha$ and $\lambda$ can be detected with the CNT loading (see Figure $6 \mathrm{~b}$ and $6 \mathrm{c}$ ). For instance, with a CNT amount of $10 \mathrm{wt} \%$ it is possible to increase the thermal conductivity at $20^{\circ} \mathrm{C}$ of the $82 \%$ with respect to the neat blend, while the

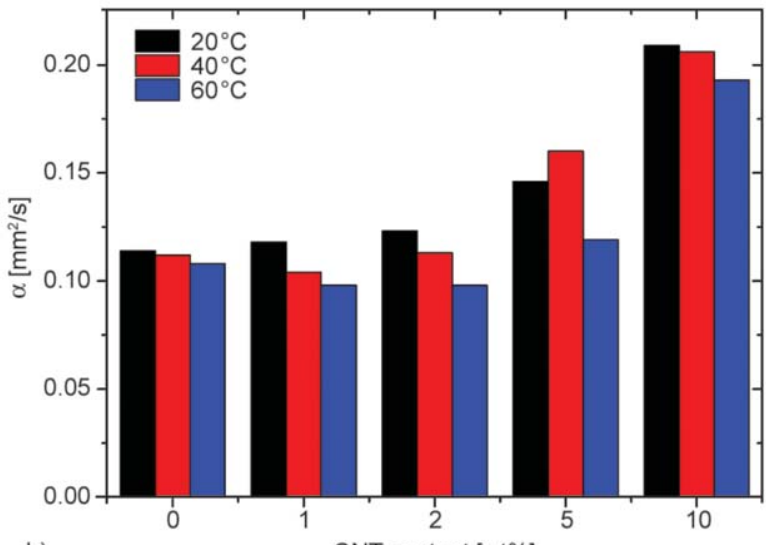

b)

CNT content $[w t \%]$

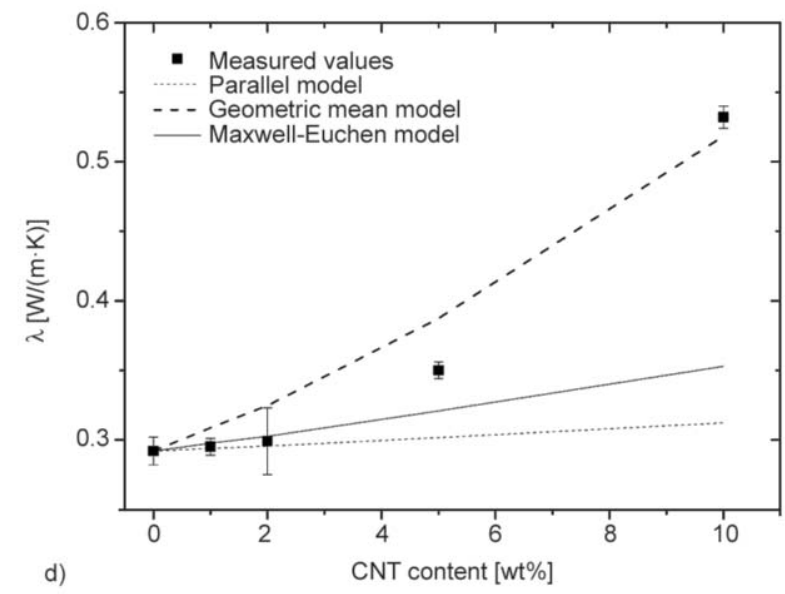

c)

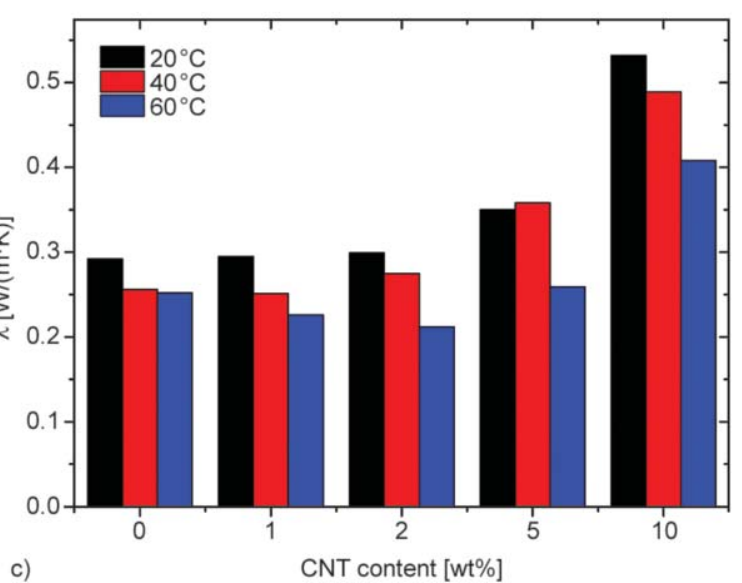

Figure 6. Thermal properties at three different temperatures of PCO/paraffin blend and of the relative nanocomposites. (a) Specific heat, (b) thermal diffusivity, (c) thermal conductivity, (d) modelization of thermal conductivity values at $20^{\circ} \mathrm{C}$. 
thermal diffusivity at $20^{\circ} \mathrm{C}$ could be increased of $83 \%$. It is therefore confirmed that heat diffusion within the material is strongly favored by nanofiller addition. Also in this case, the observed increase of the thermal conductivity at elevated filler loading could be ascribed to the formation of a percolative network within the material, constituted by nanofiller aggregates.

In order to model thermal conductivity data at $20^{\circ} \mathrm{C}$, three different expressions were considered (see Equations (3), (4) and (5) in Paragraph 2.3.5). The results of the fitting operations with the considered models are reported in Figure 6d. It is interesting to note how the geometric mean model (Equation (4)) tends to overestimate the experimental values, while parallel model (Equation (3)) and Maxwell-Eucken expression (Equation (5)) seem to catch the thermal conductivity trend until a CNT amount of $2 \mathrm{wt} \%$. For higher CNT loadings, the $\lambda$ values are largely underestimated. As reported in the section devoted to the microstructural features of the samples (Paragraph 3.1), at filler amounts higher than $5 \mathrm{wt} \%$ a strong aggregation of the CNT occurs, and also the electrical percolation threshold is reached. It is probable that the traditional models for the thermal conductivity are not able to take into account this microstructural aspect, underestimating thus $\lambda$ values above the percolation threshold.

\subsection{Finite element method (FEM) analysis}

In Figure 7a a representative image of the surface temperature distribution in the material with latent heat evolution after $1800 \mathrm{~s}$ in the PCM model is reported. It is interesting to note that the lowest temperature values are located in the corners of the material. In Figure $7 \mathrm{~b}$ a comparison between temperature values of the material with and without latent heat as a function of time is shown. Even if both the materials reach the thermal equilibrium (i.e. the external temperature) after $2500 \mathrm{~s}$, it is interesting to note how for shorter times the temperature values associated to the material with latent heat evolution are systematically higher than those of the corresponding material without latent heat evolution. For instance, the material with latent heat reaches the temperature of $-5^{\circ} \mathrm{C}$ 50 second after the material without latent heat, while it arrives at $-25^{\circ} \mathrm{C} 6.5$ minutes later.

In Figure 8a a representative image of the system representing the skin covered by the phase change material constituted by the $10 \mathrm{HC} / \mathrm{PCO} / \mathrm{CNT} 2 \%$ sample (glove model) is reported, while in Figure $8 \mathrm{~b}$ a comparison of the time required to reach a surface temperature of $4{ }^{\circ} \mathrm{C}$ at different PCM thicknesses for the material with and without latent heat is shown. As it could be expected, the critical time values increase with the glove thickness, but the values reported for the system with latent heat evolution are systematically higher than those of the corresponding glove without latent heat. Interestingly, the advantage related to the use of a thermally active material increases with the PCM thickness. For instance, with a thickness of $5 \mathrm{~mm}$, a time retardation of $170 \mathrm{~s}$ can be observed for the system with latent heat evolution. On the other hand, in Figure $8 \mathrm{c}$ a comparison of the surface temperature values after $800 \mathrm{~s}$ at different thickness for the material with and without latent heat is reported. Even in this case, the technical advantage due to the use of a thermally active material

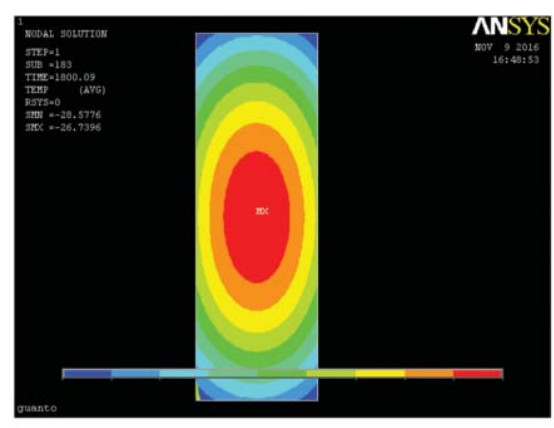

a)

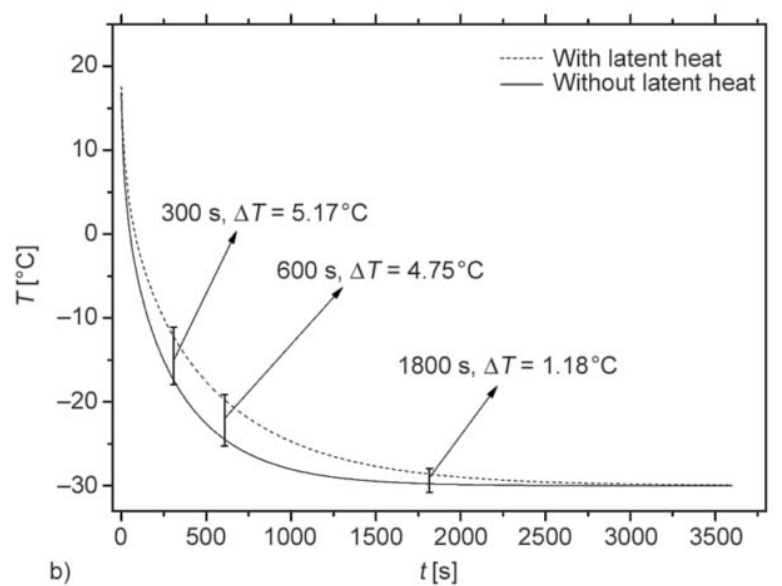

b)

Figure 7. FEM analysis of the $10 \mathrm{HC} / \mathrm{PCO} / \mathrm{CNT} 2 \%$ sample (PCM model). (a) Representative image of the surface temperature distribution after $1800 \mathrm{~s}$, (b) comparison between temperature values of the material with and without latent heat as a function of time (external temperature $-30^{\circ} \mathrm{C}$ ). 

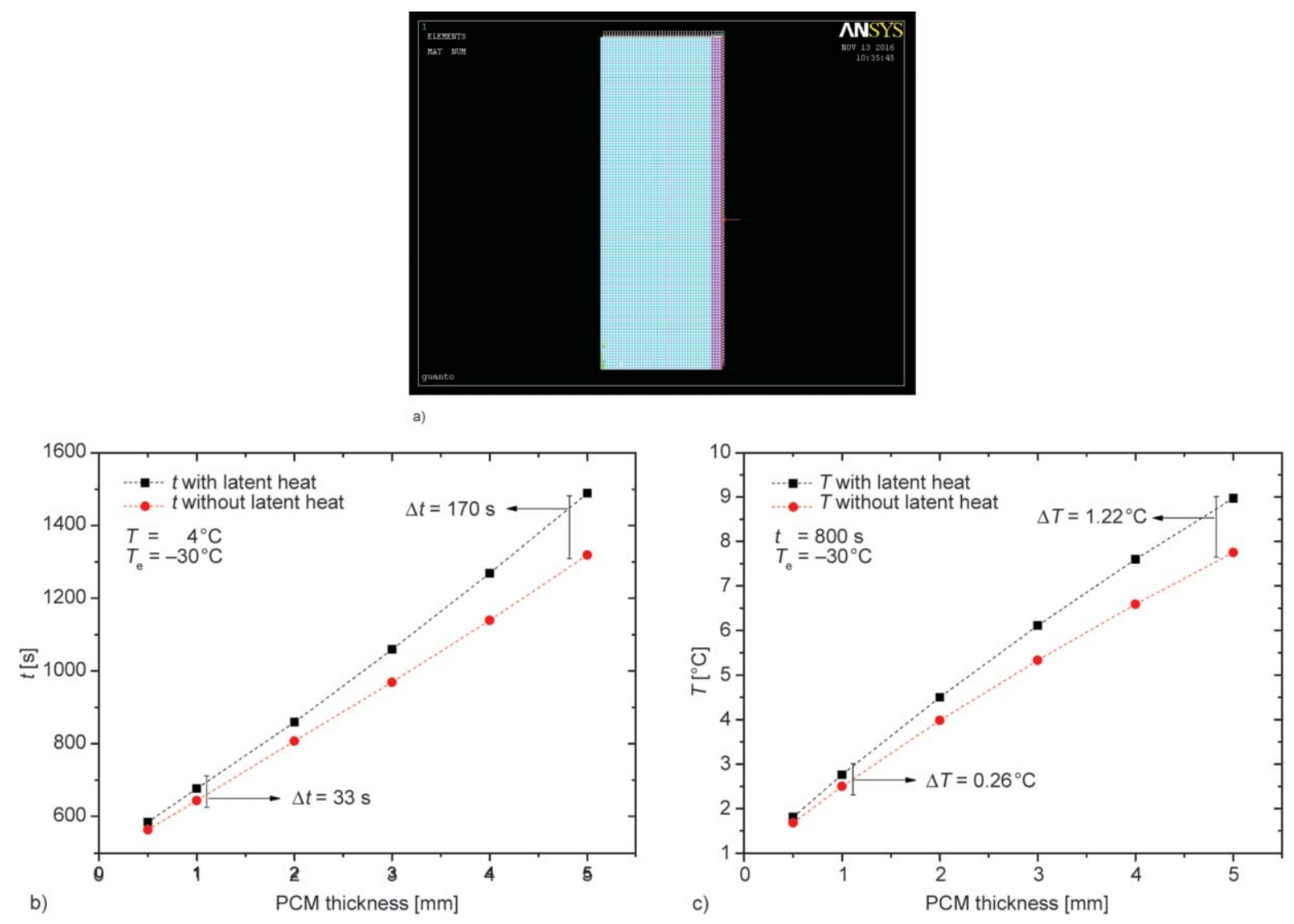

Figure 8. FEM analysis of the $10 \mathrm{HC} / \mathrm{PCO} / \mathrm{CNT} 2 \%$ sample (glove model). (a) Representative image of the system, (b) comparison of the time required to reach a surface temperature of $4{ }^{\circ} \mathrm{C}$ at different thickness for the material with and without latent heat (external temperature $-30^{\circ} \mathrm{C}$ ), (c) comparison of the surface temperature values after $800 \mathrm{~s}$ at different thickness for the material with and without latent heat (external temperature $-30^{\circ} \mathrm{C}$ ).

increases with the material thickness. As an example, with a PCM thickness of $5 \mathrm{~mm}$ it is possible to observe a temperature increase of $1.22^{\circ} \mathrm{C}$ with respect to the material without latent heat evolution. Therefore, the modeling results confirms the theoretical possibility to apply these materials in winter sport applications, and further efforts will be made in the future to improve the extent of these results.

\section{Conclusions}

Innovative phase change materials based on poly(cyclooctene)/paraffin blends, loaded with various amounts of CNTs, were prepared through a melt compounding process. The capability of these material to absorb/release thermal energy at low temperature (i.e. below $20^{\circ} \mathrm{C}$ ) was evaluated. Optical microscope and FESEM micrographs revealed how nanocomposite samples were characterized by rectangular domains of paraffin inside the encapsulating phase (i.e. PCO), and CNTs were distributed only inside the paraffin domains in forms of aggregated clusters.

The presence of two distinct crystallization peaks at -10 and at $6^{\circ} \mathrm{C}$ respectively for the paraffin and the
PCO phase detected in DSC tests confirmed that both the constituents were thermally active below room temperature, while CNT addition did not substantially alter the melting/crystallization properties of the material. CNT introduction was responsible of a noticeable increase of the mechanical properties of the materials and of their electrical conductivity. Also the thermal conductivity/diffusivity values were strongly improved upon nanofiller addition above the percolation threshold. Finite element modeling confirmed the effectiveness of these nanocomposites in increasing the time required to cool the material and/or the temperature reached by the materials at a certain time interval and therefore their efficacy as protective materials for winter sport applications.

\section{Acknowledgements}

Prof. Miroslav Slouf of the Institute of the Macromolecular Chemistry (Prague) is gratefully acknowledged for his support for the optical microscope images. The assistance of Prof. Vigilio Fontanari of the Department of Industrial Engineering of the University of Trento in assessing the finite element analysis is kindly acknowledged. 


\section{References}

[1] Zhang P., Xiao X., Ma Z. W.: A review of the composite phase change materials: Fabrication, characterization, mathematical modeling and application to performance enhancement. Applied Energy, 165, 472-510 (2016). https://doi.org/10.1016/j.apenergy.2015.12.043

[2] Wang Z., Qiu F., Yang W., Zhao X.: Applications of solar water heating system with phase change material. Renewable and Sustainable Energy Reviews, 52, 645652 (2015).

https://doi.org/10.1016/j.rser.2015.07.184

[3] Farid M. M., Khudhair A. M., Razack S. A. K., Al-Hallaj S.: A review on phase change energy storage: Materials and applications. Energy Conversion and Management, 45, 1597-1615 (2004).

https://doi.org/10.1016/j.enconman.2003.09.015

[4] Demirbas M. F.: Thermal energy storage and phase change materials: An overview. Energy Sources Part B: Economics, Planning, and Policy, 1, 85-95 (2006). https://doi.org/10.1080/009083190881481

[5] Kuznik F., David D., Johannes K., Roux J-J.: A review on phase change materials integrated in building walls. Renewable and Sustainable Energy Reviews, 15, 379 391 (2011). https://doi.org/10.1016/j.rser.2010.08.019

[6] Ostry M., Charvat P.: Materials for advanced heat storage in buildings. Procedia Engineering, 57, 837-843 (2013). https://doi.org/10.1016/j.proeng.2013.04.106

[7] Kenisarin M. M., Kenisarina K. M.: Form-stable phase change materials for thermal energy storage. Renewable and Sustainable Energy Reviews, 16, 1999-2040 (2012). https://doi.org/10.1016/j.rser.2012.01.015

[8] Robaidi A. A.: Development of novel polymer phase change material for heat storage application. International Journal of Materials Science and Applications, 2, 168-172 (2013). https://doi.org/10.11648/j.jimsa.20130206.11

[9] Borreguero A. M., Talavera B., Rodriguez J. F., Valverde J. L., Gonzalez J. L., Carmona M.: Enhancing the thermal comfort of fabrics for the footwear industry. Textile Research Journal, 83, 1754-1763 (2013). https://doi.org/10.1177/0040517513481872

[10] Gao C., Kuklane K., Holmér I.: Cooling vests with phase change materials: The effects of melting temperature on heat strain alleviation in an extremely hot environment. European Journal of Applied Physiology, 111, 1207-1216 (2011). https://doi.org/10.1007/s00421-010-1748-4

[11] Ren Y. J., Ruckman J. E.: Condensation in three-layer waterproof breathable fabrics for clothing. International Journal of Clothing Science and Technology, 16, 335347 (2004).

https://doi.org/10.1108/09556220410527255

[12] Sarier N., Onder E.: Organic phase change materials and their textile applications: An overview. Thermochimica Acta, 540, 7-60 (2012).

https://doi.org/10.1016/j.tca.2012.04.013
[13] Shim H., McCullough E. A., Jones B. W.: Using phase change materials in clothing. Textile Research Journal, 71, 495-502 (2001). https://doi.org/10.1177/004051750107100605

[14] Shin Y., Yoo D-I., Son K.: Development of thermoregulating textile materials with microencapsulated phase change materials (PCM). II. Preparation and application of PCM microcapsules. Journal of Applied Polymer Science, 96, 2005-2010 (2005).

https://doi.org/10.1002/app.21438

[15] Gin B., Farid M. M.: The use of PCM panels to improve storage condition of frozen food. Journal of Food Engineering, 100, 372-376 (2010).

https://doi.org/10.1016/j.jfoodeng.2010.04.016

[16] Chen C-R., Chou H-M., Lan N. V.: Effective heat utilization for energy saving in food and beverage thermal isolated containers. International conference on consumer electronics, communications and networks (CECNet), 4945-4948 (2011).

https://doi.org/10.1109/CECNET.2011.5768903

[17] Norton B.: Solar energy thermal technology. Springer Heidelberg (1992).

[18] Lane G.: Solar heat storage: Latent heat materials. CRC Press, Boca Raton (1986)

[19] Bal L. M., Satya S., Naik S. N.: Solar dryer with thermal energy storage systems for drying agricultural food products: A review. Renewable and Sustainable Energy Reviews, 14, 2298-2314 (2010). https://doi.org/10.1016/j.rser.2010.04.014

[20] Hasnain S. M.: Review on sustainable thermal energy storage technologies, Part I: heat storage materials and techniques. Energy Conversion and Management, 39, 1127-1138 (1998). https://doi.org/10.1016/S0196-8904(98)00025-9

[21] Abhat A.: Low temperature latent heat thermal energy storage: Heat storage materials. Solar Energy, 30, 313332 (1983).

https://doi.org/10.1016/0038-092X(83)90186-X

[22] Pillai K. K., Brinkworth B. J.: The storage of low grade thermal energy using phase change materials. Applied Energy, 2, 205-216 (1976). https://doi.org/10.1016/0306-2619(76)90025-8

[23] Trigui A., Karkri M., Boudaya C., Candau Y., Ibos L., Fois M.: Experimental investigation of a composite phase change material: Thermal-energy storage and release. Journal of Composite Materials, 48, 49-62 (2014). https://doi.org/10.1177/0021998312468185

[24] Sharma R. K., Ganesan P., Tyagi V. V., Metselaar H. S. C., Sandaran S. C.: Developments in organic solid-liquid phase change materials and their applications in thermal energy storage. Energy Conversion and Management, 95, 193-228 (2015). https://doi.org/10.1016/j.enconman.2015.01.084

[25] Li M., Wu Z.: A review of intercalation composite phase change material: Preparation, structure and properties. Renewable and Sustainable Energy Reviews, 16, 2094-2101 (2012).

https://doi.org/10.1016/j.rser.2012.01.016 
[26] Himran S., Suwono A., Mansoori G. A.: Characterization of alkanes and paraffin waxes for application as phase change energy storage medium. Energy Sources, 16, 117-128 (1994).

https://doi.org/10.1080/00908319408909065

[27] Dorigato A., Ciampolillo M. V., Cataldi A., Bersani M., Pegoretti A.: Polyethylene wax/EPDM blends as shapestabilized phase change materials for thermal energy storage. Rubber Chemistry and Technology, in press (2017). https://doi.org/10.5254/rct.82.83719

[28] Akgün M., Aydın O., Kaygusuz K.: Experimental study on melting/solidification characteristics of a paraffin as PCM. Energy Conversion and Management, 48, 669678 (2007).

https://doi.org/10.1016/j.enconman.2006.05.014

[29] Khadiran T., Hussein M. Z., Zainal Z., Rusli R.: Encapsulation techniques for organic phase change materials as thermal energy storage medium: A review. Solar Energy Materials and Solar Cells, 143, 78-98 (2015). https://doi.org/10.1016/j.solmat.2015.06.039

[30] Inaba H., Tu P.: Evaluation of thermophysical characteristics on shape-stabilized paraffin as a solid-liquid phase change material. Heat and Mass Transfer, 32, 307-312 (1997).

https://doi.org/10.1007/s002310050126

[31] Sobolciak P., Karkri M., Al-Maaded M. A., Krupa I.: Thermal characterization of phase change materials based on linear low-density polyethylene, paraffin wax and expanded graphite. Renewable Energy, 88, 372 382 (2016).

https://doi.org/10.1016/j.renene.2015.11.056

[32] Mu M. L., Basheer P. A. M., Sha W., Bai Y., McNally T.: Shape stabilised phase change materials based on a high melt viscosity HDPE and paraffin waxes. Applied Energy, 162, 68-82 (2016).

https://doi.org/10.1016/j.apenergy.2015.10.030

[33] Su J-F., Zhao Y-H., Wang X-Y., Dong H., Wang S-B.: Effect of interface debonding on the thermal conductivity of microencapsulated-paraffin filled epoxy matrix composites. Composites Part A: Applied Science and Manufacturing, 43, 325-332 (2012). https://doi.org/10.1016/j.compositesa.2011.12.003

[34] Luyt A. S., Krupa I.: Phase change materials formed by UV curable epoxy matrix and Fischer-Tropsch paraffin wax. Energy Conversion and Management, 50, 57-61 (2009).

https://doi.org/10.1016/j.enconman.2008.08.026

[35] Jeong S-G., Cha J., Kim S., Seo J., Lee J-H., Kim S.: Preparation of thermal-enhanced epoxy resin adhesive with organic PCM for applying wood flooring. Journal of Thermal Analysis and Calorimetry, 117, 1027-1034 (2014).

https://doi.org/10.1007/s10973-014-3862-8

[36] Pielichowska K., Bieda J., Szatkowski P.: Polyurethane/ graphite nano-platelet composites for thermal energy storage. Renewable Energy, 91, 456-465 (2016). https://doi.org/10.1016/j.renene.2016.01.076
[37] Pielichowska K., Pielichowski K.: Phase change materials for thermal energy storage. Progress in Materials Science, 65, 67-123 (2014). https://doi.org/10.1016/j.pmatsci.2014.03.005

[38] Sari A., Akcay M., Soylak M., Onal A.: Polymer-stearic acid blends as form-stable phase change material for thermal energy storage. Journal of Scientific and Industrial Research, 64, 991-996 (2005).

[39] Sari A., Soylak M.: Equilibrium and thermodynamic studies of stearic acid adsorption on Celtek clay. Journal of the Serbian Chemical Society, 72, 485-494 (2007). https://doi.org/10.2298/jsc0705485s

[40] Liu C., Chun S. B., Mather P. T., Zheng L., Haley E. H., Coughlin E. B.: Chemically cross-linked polycyclooctene: Synthesis, characterization, and shape memory behavior. Macromolecules, 27, 9868-9874 (2002).

https://doi.org/10.1021/ma021141j

[41] Dorigato A., Pegoretti A.: Effects of carbonaceous nanofillers on the mechanical and electrical properties of crosslinked poly(cyclooctene). Polymer Egnineering and Science, in press (2017).

https://doi.org/10.1002/pen.24449

[42] Dorigato A., Pegoretti A.: Evaluation of the shape memory behavior of a poly(cyclooctene) based nanocomposite device. Polymer Engineering and Science, in press (2016).

https://doi.org/10.1002/pen.24590

[43] Nomura T., Tabuchi K., Zhu C., Sheng N., Wang S., Akiyama T.: High thermal conductivity phase change composite with percolating carbon fiber network. Applied Energy, 154, 678-685 (2015). https://doi.org/10.1016/j.apenergy.2015.05.042

[44] Py X., Olives R., Mauran S.: Paraffin/porous-graphitematrix composite as a high and constant power thermal storage material. International Journal of Heat and Mass Transfer, 44, 2727-2737 (2001).

https://doi.org/10.1016/S0017-9310(00)00309-4

[45] Progelhof R. C., Throne J. L., Ruetsch R. R.: Methods for predicting the thermal conductivity of composite systems: A review. Polymer Engineering and Science, 16, 615-625 (1976). https://doi.org/10.1002/pen.760160905

[46] Parker W. J., Jenkins R. J., Butler C. P., Abbott G. L.: Flash method of determining thermal diffusivity, heat capacity, and thermal conductivity. Journal of Applied Physics, 32, 1679-1684 (1961). https://doi.org/10.1063/1.1728417

[47] Nielsen L. E.: The thermal and electrical conductivity of two-phase systems. Industrial and Engineering Chemistry Fundamentals, 13, 17-20 (1974). https://doi.org/10.1021/i160049a004

[48] Kim Y. A., Kamio S., Tajiri T., Hayashi T., Song S. M., Endo M., Terrones M., Dresselhaus M. S.: Enhanced thermal conductivity of carbon fiber/phenolic resin composites by the introduction of carbon nanotubes. Applied Physics Letters, 90, 093125/1-093125/8 (2007). https://doi.org/10.1063/1.2710778 
[49] Hamilton R. L., Crosser O. K.: Thermal conductivity of heterogeneous two-component systems. Industrial and Engineering Chemistry Fundamentals, 1, 187-191 (1962). https://doi.org/10.1021/i160003a005

[50] Dorigato A., Moretti V., Dul S., Unterberger S. H., Pegoretti A.: Electrically conductive nanocomposites for fused deposition modelling. Synthetic Metals, 226, 7-14 (2017).

https://doi.org/10.1016/j.synthmet.2017.01.009

[51] Bo H., Gustafsson E. M., Setterwall F.: Tetradecane and hexadecane binary mixtures as phase change materials (PCMs) for cool storage in district cooling systems. Energy, 24, 1015-1028 (1999).

https://doi.org/10.1016/S0360-5442(99)00055-9
[52] Dresselhaus M. S., Dresselhaus G., Avouris P.: Carbon nanotubes: Synthesis, structure, properties, and applications. Springer, Berlin (2003).

[53] Dorigato A., Dzenis Y., Pegoretti A.: Filler aggregation as a reinforcement mechanism in polymer nanocomposites. Mechanics of Materials, 61, 79-90 (2013). https://doi.org/10.1016/j.mechmat.2013.02.004

[54] dos Santos W. N., de Sousa J. A., Gregorio R.: Thermal conductivity behaviour of polymers around glass transition and crystalline melting temperatures. Polymer Testing, 32, 987-994 (2013).

https://doi.org/10.1016/j.polymertesting.2013.05.007 